\title{
Geomagnetic Polarity Timescales and Reversal Frequency Regimes
}

\author{
William Lowrie \\ Institute of Geophysics, ETH Hönggerberg, Zürich, Switzerland \\ Dennis V. Kent \\ Department of Geological Sciences, Rutgers University, Piscataway, New Jersey \\ \& Lamont-Doherty Earth Observatory, Palisades, New York
}

An analysis of geomagnetic reversal history is made for the most reliable polarity timescales covering the last 160 Myr. The timescale of Cande and Kent [1995] (CK95) is the optimum representation of Cenozoic and Late Cretaceous polarity history, and the timescale of Channell et al. [1995] (CENT94) best represents the Early Cretaceous and Late Jurassic. The CK95 timescale can be divided into two nearly linear segments at Chron C12r. The lengths of chrons in the younger segment have no systematic trend, and so this part of the polarity sequence is considered to be stationary for statistical analysis. The mean chron length is $0.248 \mathrm{Myr}$ and the gamma index, $k$, for the distribution of chron lengths is $1.6 \pm 0.4$; inserting just 8 additional short subchrons that have been verified from magnetostratigraphic studies as polarity reversals reduces the mean chron length to $0.219 \mathrm{Myr}$ and $k$ to $1.3 \pm 0.3$. The older segment is stationary if the two long polarity chrons $\mathrm{C} 33 \mathrm{n}$ and $\mathrm{C} 33 \mathrm{r}$ adjacent to the Cretaceous Normal Polarity Superchron are omitted; in this case the mean chron length is $0.749 \mathrm{Myr}$ and $k$ is $1.2 \pm 0.4$. The chrons in the CENT94 timescale are stationary with mean length $0.415 \mathrm{Myr}$ and $k$ is $1.3 \pm 0.3$. The gamma indices of the chron distributions are not significantly different from a Poisson distribution $(k=1)$, which implies that the reversal process is essentially free of long-term memory. However, if the mean chron duration is an indicator of stability of the reversal process, it appears that long lasting episodes of stable behavior may be followed by abrupt change to another stable regime with a markedly different reversal frequency. There is no significant change of the gamma index from one regime to another although the mean polarity chron length changes by more than a factor of three. This would imply that the probability of a reversal may be constant within each regime but varies inversely with mean interval length from regime to regime.

Timescales of the Paleomagnetic Field Geophysical Monograph Series 145

Copyright 2004 by the American Geophysical Union 10.1029/145GM09

\section{GEOMAGNETIC POLARITY TIMESCALES}

The history of polarity reversals of Earth's magnetic field is well known for the last $160 \mathrm{Myr}$ from the record of oceanic magnetic anomalies. Three distinct episodes are defined (Figure 1). The youngest corresponds to the magnetic anomalies 


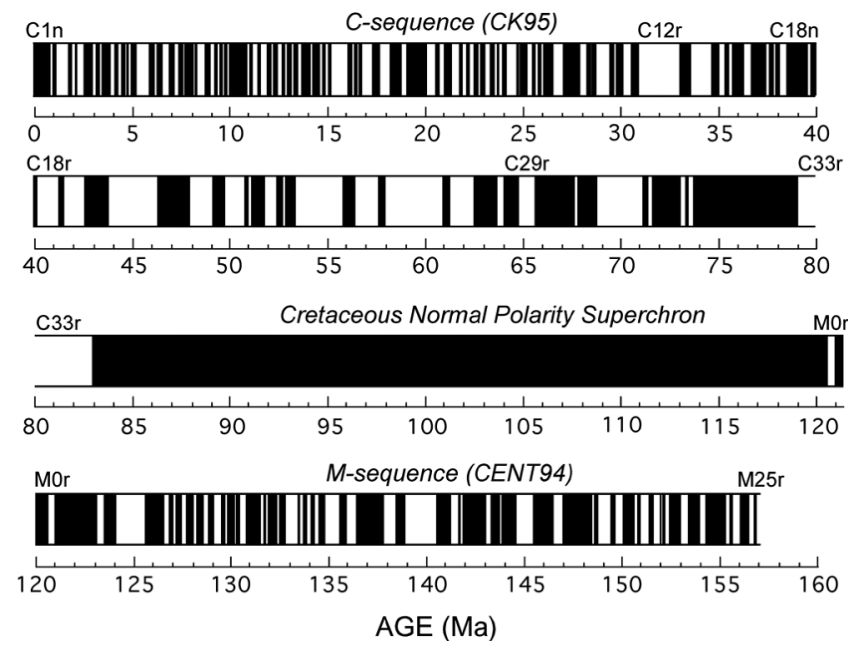

Figure 1. Composite timescale incorporating the current optimum timescales for the $\mathrm{C}$-sequence and $\mathrm{M}$-sequence magnetic anomalies.

formed in the Cenozoic and Late Cretaceous, which are here referred to as the $\mathrm{C}$-sequence. This is separated in the oceanic record from the older M-sequence of anomalies, formed in Late Jurassic and early Cretaceous times, by the Cretaceous Quiet Zone in which correlated magnetic anomalies are absent. The corresponding Cretaceous Normal Polarity Superchron (CNPS) represents a time interval in which Earth's magnetic field evidently did not reverse polarity. Magnetic polarity stratigraphy studies in continental exposures of marine limestones have confirmed the main features of the $\mathrm{C}$ - and $\mathrm{M}$-sequences as reflecting reversals of the geomagnetic field and correlated most stage boundaries from the Late Jurassic to the present to the corresponding marine magnetic polarity records [Alvarez et al., 1977; Channell and Erba, 1992; Channell et al., 2000; Channell et al., 1979; Channell and Medizza, 1981; Lowrie and Alvarez, 1981; Lowrie and Alvarez, 1984; Lowrie et al., 1982; Lowrie and Channell, 1984; Ogg et al., 1984].

Several magnetic polarity timescales have been developed for each of the two reversal sequences. In each case the magnetic anomalies are first interpreted as a block model of oceanic crustal magnetizations of alternating polarity. Multiple profiles are combined to minimize local minor differences in spreading rate on any given profile. The spacings of block boundaries in the resultant composite block model then define the relative lengths of polarity intervals in the timescale. Magnetic stratigraphy has played an important role in dating the polarity sequences by correlating key biostratigraphic stage boundaries or other radiometrically dated datum-levels to the $\mathrm{C}$ - and M-sequence polarity record. The rest of the timescale is dated by conversion of polarity boundary locations to numeric ages by interpolation between the tie-levels. In order to avoid sudden changes in apparent spreading rate at tie-points a bestfit straight line or smooth curve may be fitted to the correlation points. The fundamental assumption here is that sea-floor spreading in selected corridors was constant or at least smoothly varying over long intervals of time, which is justified at least to first order, but is nonetheless a potential source of error in determining block widths and chron durations. The 'absolute ages' of the tie-levels are much less exactly known than the relative lengths of the polarity intervals. In addition to the errors of absolute dating there are stratigraphic errors in relating the radiometrically dated rocks to the biostratigraphically located stage boundary or other datum-levels.

The polarity timescale for each reversal sequence has evolved, accompanying improvements in the resolution of magnetic anomalies, definition of oceanic block models, magnetostratigraphic correlation and the dating of calibration points. The pioneering timescale of Heirtzler et al. [1968], hereafter referred to as HDHPL68, was derived from comparison of marine magnetic profiles in different oceans, from which a block model of crustal magnetization based on a highly levered extrapolation of sea-floor spreading history in the South Atlantic was chosen as best representative for anomalies from the present to the Late Cretaceous (anomaly 32). The Late Cretaceous anomaly sequence was refined and extended to anomaly 33r by analyses of North Pacific and North Atlantic marine profiles [Cande and Kristoffersen, 1977]. Magnetostratigraphic correlation of the Cretaceous-Tertiary boundary to anomaly 29r [Lowrie and Alvarez, 1977] provided better dating of the older end of the sequence. This resulted in a more accurate timescale [LaBrecque et al., 1977], hereafter referred to as LKC77. These reversal sequences formed the basis of several subsequent timescales [Mead, 1996].

A detailed re-evaluation of the $\mathrm{C}$-sequence marine magnetic anomalies and the corresponding block models led to the development of an improved timescale [Cande and Kent, 1992a]. Age calibration was achieved by fitting a smooth (cubic spline) curve to nine calibration levels for South Atlantic spreading history. An updated version [Cande and Kent, 1995], hereafter referred to as CK95, incorporates improved ages for the calibration levels. It is used as reference timescale for the Late Cretaceous and Cenozoic (C-sequence) in the present paper.

Investigations of magnetic anomalies on the Hawaiian, Japanese and Phoenix lineations in the North Pacific and the Keathley lineations in the North Atlantic were integrated into a polarity sequence and timescale covering marine magnetic anomalies M0 to M25 [Larson and Hilde, 1975], which formed the basis for subsequent polarity timescales. Oceanic crust older than the sequence M0-M25 was at first thought to be devoid of lineated magnetic anomalies and was called the Jurassic Quiet Zone by analogy to its Cretaceous counterpart. 
Magnetic lineations with low amplitude were described in the youngest part of the Jurassic Quiet Zone and modeled by a block model of polarity characterized by decreasing magnetization with increasing age [Cande et al., 1978]. The M-sequence was extended thereby to M29.

The dating of M-sequence polarity reversals relied initially on estimated bottom ages in DSDP holes drilled on or near the lineations. Subsequent timescales have been formed by attaching better calibration ages to the sequence [Harland et al., 1990; Kent and Gradstein, 1985]. These usually consist of a group of ages at each end, with linear interpolation and extrapolation serving to date reversal boundaries between and beyond the tie-points. Channell et al. [1995] compared block models for the anomalies on the Hawaiian, Japanese, Phoenix and Keathley lineations and decided on a new Hawaiian block model with optimum approximation to constant spreading rate, covering magnetic polarity chrons CM0 to CM29. The calibration ages gave favorable comparison with stage boundary ages from magnetostratigraphic correlations. This timescale, hereafter CENT94, is chosen as reference for the $\mathrm{M}$-sequence in this paper. The combined polarity timescales represented by CK95 and CENT94 delineate a Cretaceous Normal Polarity Superchron (CNPS) that began at $120.6 \mathrm{Ma}$ and lasted until 83.0 Ma (Figure 1).

Later airborne and marine deep-tow magnetometer surveys have suggested that the young end of the Jurassic Quiet Zone is characterized by low amplitude, short wavelength anomalies that are lineated [Handschumacher et al., 1988; Sager et al., 1998]. If they are due to short polarity chrons, they extend the polarity history associated with the M-sequence of anomalies from CM29 to CM41, and suggest that the Jurassic Quiet Zone may have formed during an interval of rapidly varying magnetic polarity [Handschumacher et al., 1988; Sager et al., 1998], rather than constant polarity, as inferred for the Cretaceous Quiet Zone. However, the pre-M29 anomalies resemble "tiny wiggles" observed within the C-sequence and many of the features may thus be due to paleointensity fluctuations [Cande and Kent, 1992b]. Magnetostratigraphic investigations of Middle to Late Oxfordian limestone sections [Steiner et al., 1985] have described magnetozones with normal and reverse polarity, but these have not yet been correlated satisfactorily to the marine polarity record. In the absence of such confirmation, the possible chrons CM29-CM41 are not discussed further here.

\section{REVERSAL FREQUENCY SINCE THE LATE JURASSIC}

The variation of reversal behavior in the composite timescale CK95+CENT94 is conveniently displayed by plotting the age of each reversal against the order of its occur-

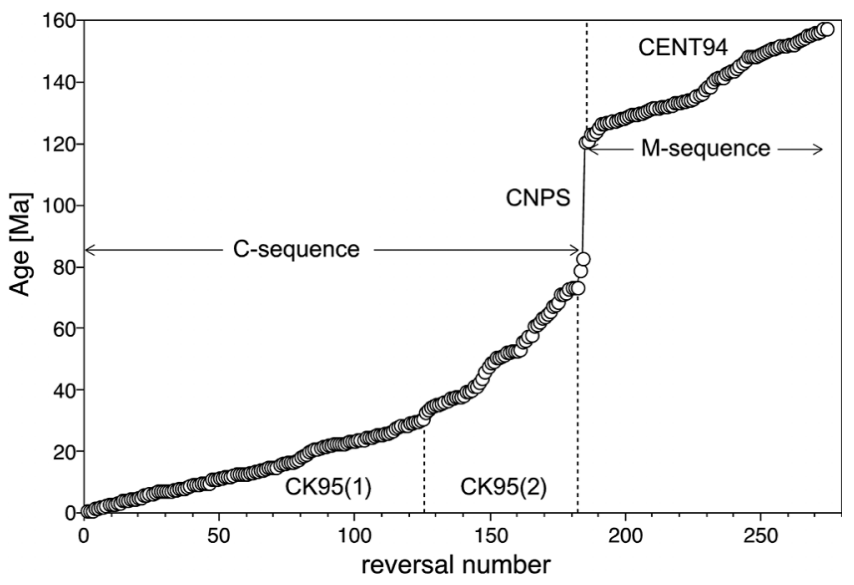

Figure 2. Ages of magnetic reversals in the Cenozoic and Meso-zoic oceanic anomaly sequences, plotted against their age order.

rence (Figure 2). The CENT94 data closely define a straight line. The $\mathrm{C}$-sequence can be divided into two nearly linear segments that intersect near Chron C12r at about 31-33 Ma. We subdivide the polarity sequence at Chron C12r because this 2.1 Myr chron lasts about an order of magnitude longer than the average subsequent chron. Two polarity intervals, C33n and C33r, immediately following the CNPS are several times longer than any of the following chrons. They are the second and third longest chrons in the entire $160 \mathrm{Ma}$ sequence and may have closer affinity to the CNPS than to the rest of the polarity sequence. For the purposes of further analysis we define the segment younger than $\mathrm{C} 12 \mathrm{r}$ as CK95(1) and the older segment (including C12r but without C33n and C33r) as CK95(2). This choice is somewhat arbitrary but it allows us to subdivide the polarity sequence into the longest possible linear segments without excluding any chrons other than C33n and C33r. Linear segments imply that the reversal process is stationary within the segment and allow calculation of representative statistical parameters. Mean polarity interval lengths are 0.248 Myr for CK95(1), 0.749 Myr for CK95(2), and 0.415 Myr for CENT94. The CNPS, the 37.6 Myr Cretaceous interval of constant normal polarity, is evident as an abrupt discontinuity between the $\mathrm{M}$ - and $\mathrm{C}$-sequences and may represent a prolonged disruption of the reversal process.

\section{STATISTICAL ANALYSIS OF CHRON LENGTHS}

\subsection{Statistical Models of Polarity Chron Durations}

The observed durations of polarity chrons $\left(10^{4}-10^{7} \mathrm{yr}\right)$ are typically much longer than the characteristic time constants of magnetohydrodynamic processes in Earth's liquid core $\left(10^{2}-10^{4}\right.$ yr). To account for the discrepancy, Cox [1968] proposed a sto- 
chastic model in which the instantaneous probability of a reversal is constant. For a low probability of occurrence the lengths $(x)$ of polarity chrons conform to an exponential (Poisson) distribution with probability density function $p(x)$ given by

$$
p(x)=\frac{1}{\mu} \exp \left(-\frac{x}{\mu}\right)
$$

in which $\mu$ is the mean chron length.

This model was not, however, obviously supported by the known geomagnetic polarity records, which were notably lacking in short polarity chrons. Instead, the observed distribution of chron durations usually agreed better with a gamma distribution [Naidu, 1970], which has the probability density function

$$
p(x)=\left(\frac{k}{\mu}\right)^{k} \frac{x^{k-1}}{\Gamma(k)} \exp \left(-k \frac{x}{\mu}\right)
$$

in which $k$ is the gamma index of the distribution and $?(k)$ is the gamma function of $k$, defined as

$$
\Gamma(k)=\int_{0}^{\infty} x^{k-1} e^{-x} d x
$$

The exponential distribution corresponds to $k=1$. A gamma distribution of chrons implies that the reversal process has a memory; the probability of a reversal is not constant with time. Immediately after the occurrence of a reversal the probability of a new one is at first very low and increases with time. This would suggest that the reversal process has a recovery time during which the probability of a reversal is gradually restored.

Estimation of the gamma index $k$ usually employs the maximum likelihood method, first applied by Naidu [1970] to fixed windows and by Phillips [1977] to a moving window. In this method, the best estimate of $k$ is the solution of the equation

$$
\ln k-\Psi(k)=\ln \mu-\frac{1}{N} \sum_{N} \ln x
$$

where $\Psi(k)=\mathrm{d}\{\ln \Gamma(\mathrm{k})\} / \mathrm{dk}$ is the digamma function. For small numbers of chrons, McFadden [1984] recommends the substitution of $(N-1)$ for $N$. The variance $(\sigma 2)$ of $k$ is given by the relationship [Phillips, 1977]

$$
\sigma^{2}(k)=\frac{1}{N\left(\Psi^{\prime}(k)-\frac{1}{k}\right)}
$$

where $\Psi^{\prime}(\mathrm{k})=\mathrm{d} \Psi(\mathrm{k}) / \mathrm{dk}$ is the trigamma function. The $\pm 2 \sigma$ confidence limits of $k$ may be estimated from this equation.

\subsection{Results of Earlier Statistical Analyses}

Non-stationarity of the reversal sequences complicates statistical analyses of the chron durations. Naidu [1970] analyzed the statistical properties of the HDHPL68 time-scale

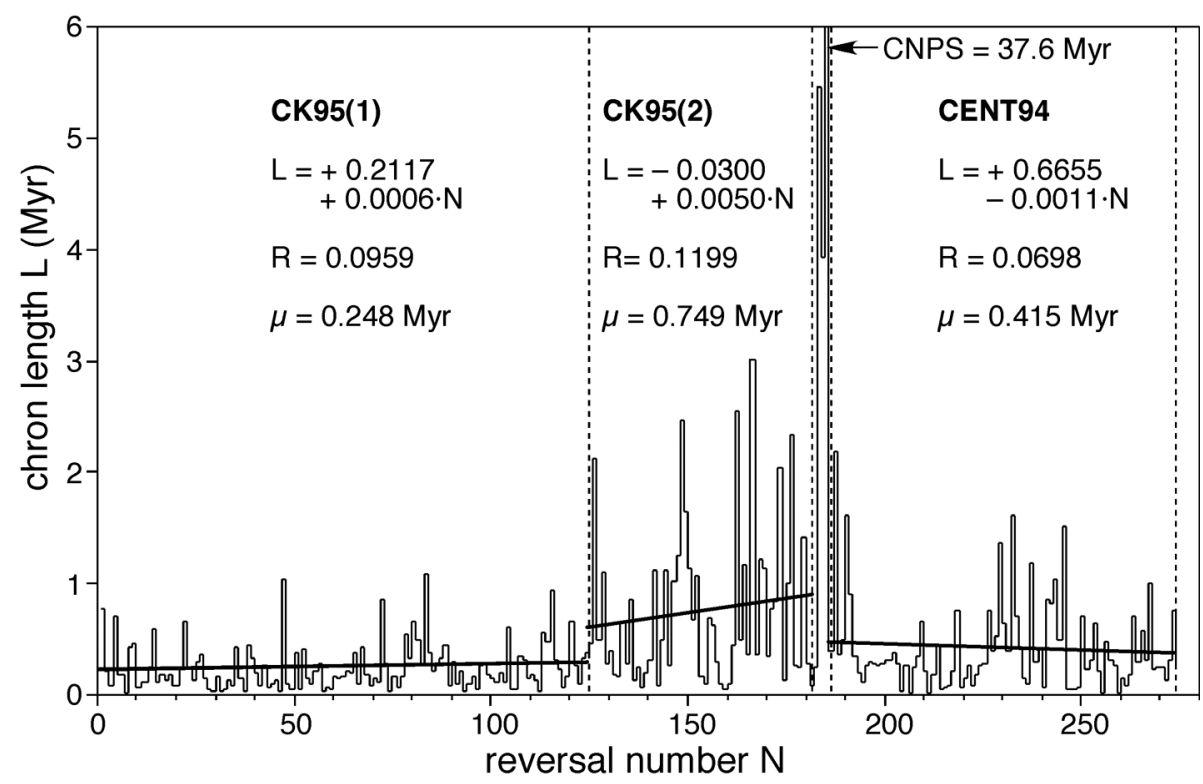

Figure 3. Polarity chron lengths (Myr) in three segments of the CK95 and CENT94 timescales, in which linear fits have non-significant slopes. 

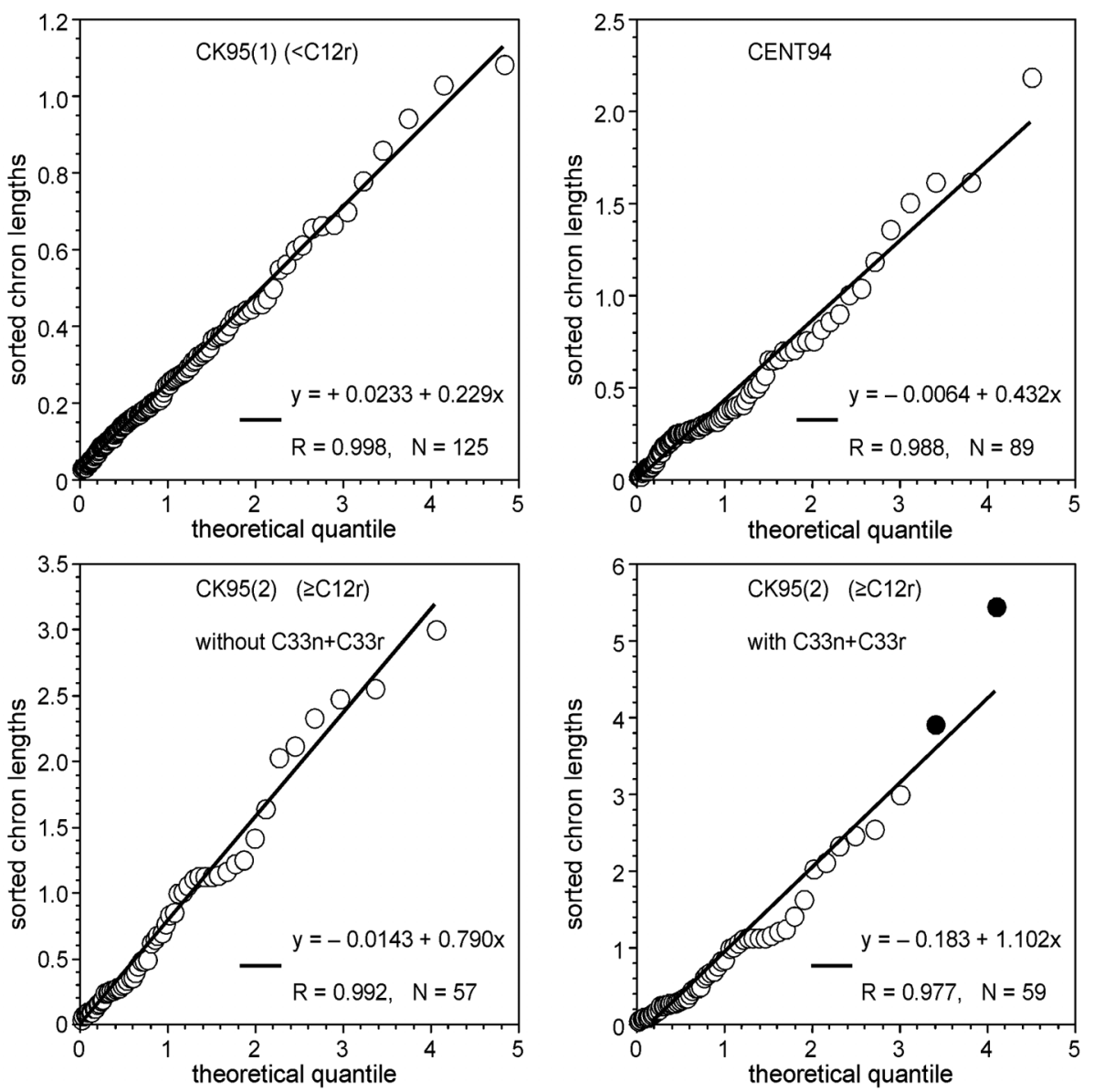

Figure 4. Quantile-quantile plots for the stationary timescale segments CK95(1), CENT94, and CK95(2) show visual agreement of the distributions of chron lengths (Myr) with a Poisson (exponential) distribution; addition of chrons C33n and C33r to CK95(2) gives a poorer fit.

within successive short windows of 8 Myr width. The assumption was made that the sequence was stationary in each short window. The gamma index was estimated to be $k=2$ for $\mathrm{C}$-sequence polarity chrons younger than $48 \mathrm{Ma}$ and $k=3.6$ for chrons older than $56 \mathrm{Ma}$.

A disadvantage of using fixed-width time windows is that the number of chrons in each window is different, which for small numbers might influence interpretation of the statistical properties. To obviate this problem Phillips [1977] analyzed the HDHPL68 timescale with a moving window containing a constant number of polarity intervals. This method has the disadvantage that each window represents a variable length of time at different points in the sequence. Moreover, the window typically includes a rather small number of chrons for robust statistical analysis. For chrons younger than the discontinuity at $45 \mathrm{Ma}$, the gamma index was $k=1.55$, but the analysis gave different values of $k=2.28$ and $k=1.19$ for the distributions of normal and reverse chrons, respectively. This was interpreted as indicating that the normal and reverse polarity states of Earth's magnetic field have different stabilities.

Unfortunately, the pioneering HDHPL68 timescale was incomplete and contained some erroneously interpreted polarity intervals, which gave rise to an artificial discontinuity in reversal rate at about $45 \mathrm{Ma}$. Thus the statistical analyses of this timescale have only historical significance.

Lowrie and Kent [1983] analyzed the improved LKC77 timescale using a moving window of constant 8 Myr width. They found values of $k=1.52$ for the stationary part of LKC77 younger than $40 \mathrm{Ma}$; values of $k=1.90$ and $k=1.28$ were found for the normal and reverse chrons, respectively, in this interval. McFadden and Merrill [1984] analyzed the LKC77 timescale using 25-interval wide moving windows and obtained an optimum value of $k=1.25$, with a $95 \%$ confidence range of 1.02 to 1.55 . The difference in $k$ between the normal and reverse polarity states was attributed to over-sen- 

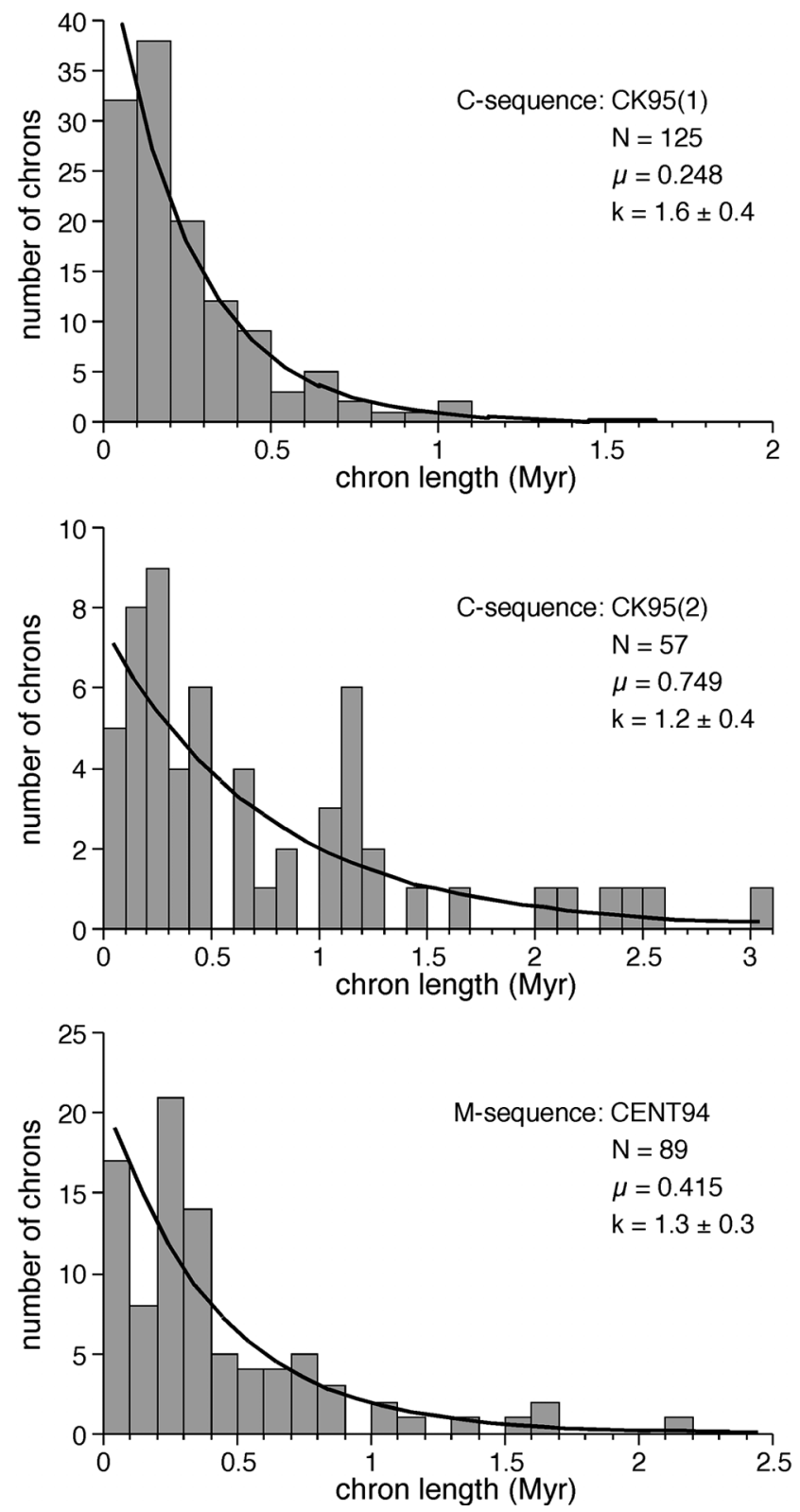

Figure 5. Histograms of chron lengths (Myr) in stationary timescale segments CK95(1), CK95(2), and CENT94 are uneven but show a lack of short chrons. The solid lines are the best fit exponential curves.

sitivity of the analytical method rather than being a real feature of the geomagnetic field.

A moving window analysis creates a false visual impression that the data set is larger than it really is; e.g., using a 25-point moving window, only every 25 th analysis is independent. Ideally the entire timescale can be detrended by fitting a sui timevarying function for the mean value. Lutz and Watson [1988] and Gaffin [1989] modeled reversal rates with aperiodic func- tions; Lowrie [1997] proposed using low-order polynomials to represent the non-stationary mean chron length. Marzocchi [1997] detrended the CK95 timescale by fitting an exponential to the reversal rate and obtained $k=1.4 \pm 0.4$ for the full timescale. He also found the part of CK95 younger than $30 \mathrm{Ma}$ to be stationary without detrending and obtained values of $k$ $=1.6 \pm 0.4$ for this segment.

\section{GAMMA INDEX ESTIMATION FOR C-SEQUENCE AND M-SEQUENCE CHRONS}

A plot of the lengths of individual polarity chrons in the composite timescale against their occurrence [Gallet and Courtillot, 1995] is shown in Figure 3. Straight lines were fitted by least squares to the chron lengths and the Student t-statistic was used to evaluate the confidence levels of the slopes. The best-fit line to CENT94, with 89 polarity intervals, has slope $0.0011 \pm 0.0033$ and is not significant. This conclusion that there is no significant trend in CENT94 was also reached by Hulot and Gallet [2003] using a more sophisticated analysis of stationarity proposed by McFadden and Merrill [2000]. The slope of the linear segment CK95(1), with 125 polarity intervals, is $0.0006 \pm 0.0011$ and is also not significant. These segments may be considered as stationary. If the two very long polarity chrons $\mathrm{C} 33 \mathrm{n}$ and $\mathrm{C} 33 \mathrm{r}$ are included in the analysis of segment CK95(2), the linear regression has slope $0.0172 \pm 0.0145$ and is marginally significant. However, if the two chrons are omitted, the best-fit line to the remaining 57 polarity intervals has slope $0.0050 \pm 0.0112$ and is not significant.

The segments CK95(1), CK95(2) without C32r and C33r, and CENT94 are stationary. A quantile-quantile (Q-Q) test [Fisher et al., 1987] can be applied to the stationary segments to test visually how well the distributions of chron lengths conform to a theoretical distribution, in this case the Poisson (exponential) distribution. To prepare this diagram, the observed chrons are ranked in order of length and plotted against the theoretical quantile (Figure 4). The linear fits indicate good agreement with the Poisson distribution, except for CK95(2) when the long chrons C33n and C33r are included. This disagreement with the rest of the population is further justification for omitting these two anomalously long chrons, which last 5.5 Myr and 3.9 Myr, respectively and together represent an appreciable fraction of the $83 \mathrm{Myr} \mathrm{C}$-sequence. Their durations and location at the end of the CNPS suggest that $\mathrm{C} 33 \mathrm{n}$ and $\mathrm{C} 33 \mathrm{r}$ might be more closely associated with the kind of field behavior in the CNPS, which lasted 37.6 $\mathrm{Myr}$, rather than the more rapidly reversing later $\mathrm{C}$-sequence.

The maximum likelihood method was employed to determine the optimum gamma indices $k$ for the distributions of chron lengths in each segment. Histograms of the chron lengths 

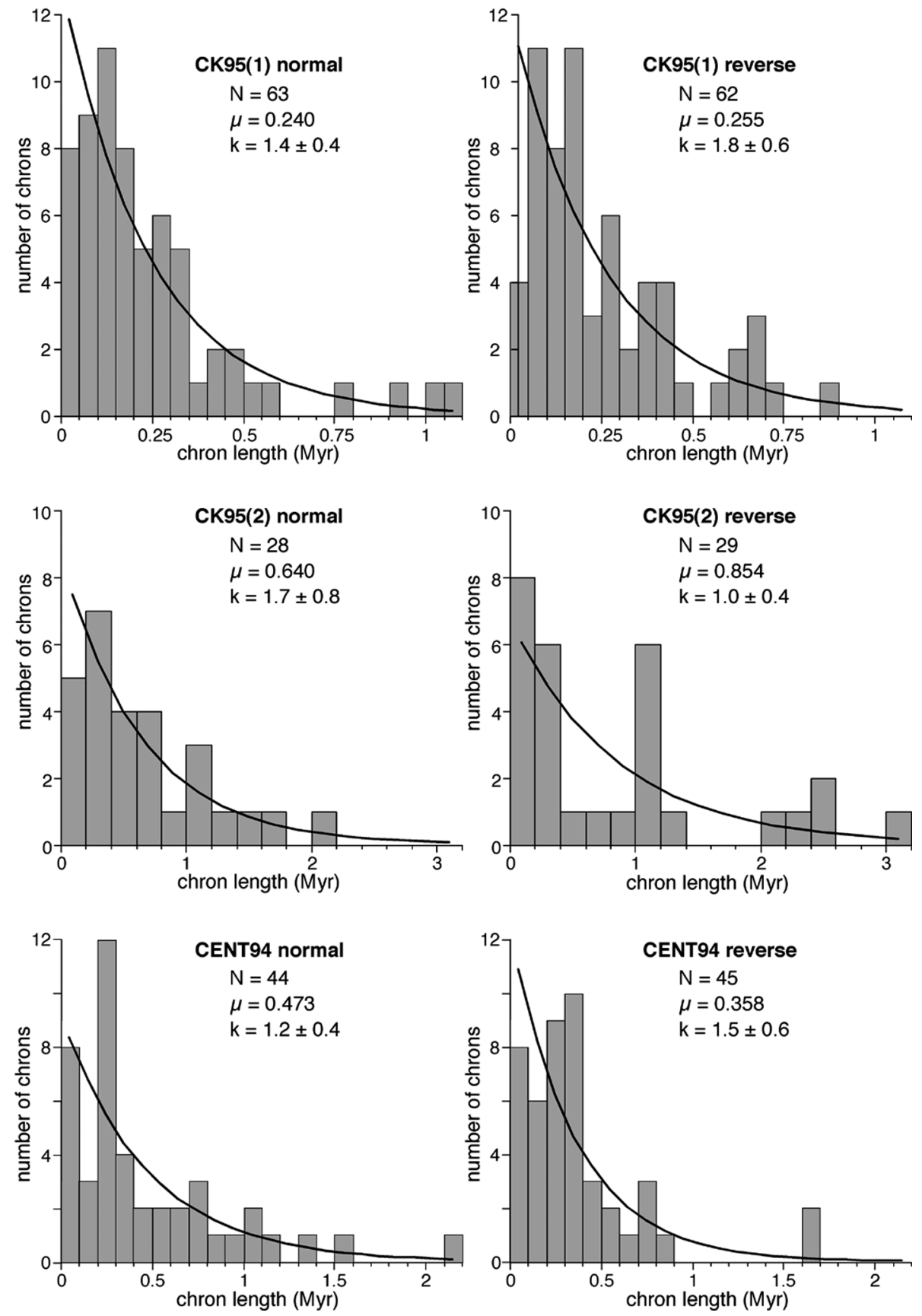

Figure 6. Distributions of normal and reverse polarity chron lengths (Myr) in the stationary timescale segments CK95(1), CK95(2), and CENT94. Solid lines are best fit exponential curves.

are shown in Figure 5 and for the separate distributions of normal and reverse chrons in Figure 6. The values of $k$ obtained for both polarity sets are in the range $1.2 \leq \mathrm{k} \leq 1.6$ (Table 1 ). For CK95(1) the $2 \sigma$ limits do not include $k=1$, but for CK95(2) and CENT94 they do (Figure 7). When separated by polarity, only the reverse polarity set for CK95(1) does not include $k=1$.

\section{THE CRETACEOUS NORMAL POLARITY SUPERCHRON}

The uniform polarity of the CNPS has been challenged by reports of reversed polarity zones in the Aptian and Albian. Reversely magnetized Aptian marls were reported at a site near Valdorbia in the Umbrian Apennines [VandenBerg and 
Table 1. Number of chrons $(N)$, range of ages $(\mathrm{Ma})$, mean chron duration $(\mu, \mathrm{Myr})$, maximum likelihood estimate of the gamma index $(k)$, and $\pm 2 \sigma$ range of $k$ in segments of the composite timescale used in this paper. CK95(1)+ includes 8 additional subchrons listed in Table 2

\begin{tabular}{lrrrrr}
\hline Timescale & $N$ & Age range & $\mu$ & $k$ & $\pm 2 \sigma(k)$ \\
\hline & & & & & \\
CK95(1), N\&R & 125 & $0-30.9$ & 0.248 & 1.56 & \pm 0.36 \\
CK95(1), N & 63 & & 0.240 & 1.41 & \pm 0.45 \\
CK95(1), R & 62 & & 0.255 & 1.75 & \pm 0.58 \\
CK95(1)+, N\&R & 141 & $0-30.9$ & 0.219 & 1.33 & \pm 0.29 \\
CK95(1)+, N & 71 & & 0.216 & 1.13 & \pm 0.34 \\
CK95(1)+, R & 70 & & 0.222 & 1.63 & \pm 0.50 \\
CK95(2), N\&R & 57 & $30.9-73.6$ & 0.749 & 1.18 & \pm 0.40 \\
CK95(2), N & 28 & & 0.640 & 1.65 & \pm 0.81 \\
CK95(2), R & 29 & & 0.854 & 0.96 & \pm 0.45 \\
CENT94, N\&R & 89 & $120.6-157.5$ & 0.415 & 1.26 & \pm 0.34 \\
CENT94, N & 44 & & 0.473 & 1.15 & \pm 0.44 \\
CENT94, R & 45 & & 0.358 & 1.45 & \pm 0.56 \\
\hline
\end{tabular}

Wonders, 1976]. The magnetozone occurred in strongly hematized redbeds and was not found in other coeval Tethyan magnetostratigraphic sections. However, Tarduno [1990] found reversely magnetized samples of Aptian age in DSDP Site 463. Although reversely magnetized beds were found in the Albian Fucoid Marls in the Umbrian Contessa section, their significance as polarity chrons was cast in doubt by rock magnetic evidence that the magnetozone could be remagnetized [Tarduno et al., 1992]. Possible correlative short magnetozones in cores recovered from the Deep Sea Drilling Program and Ocean Drilling Program may be due to accidentally inverted core segments. There is presently no convincing evidence that refutes the interpretation of the CNPS as an uninterrupted lengthy period of constant normal polarity, but there are strong indications that it may be characterized by paleointensity fluctuations [Cronin et al., 2001].

\section{EFFECTS OF CRYPTOCHRONS ON POLARITY CHRON DISTRIBUTIONS}

Many short wavelength, low amplitude magnetic anomalies ("tiny wiggles") are interspersed in the marine magnetic record. It is uncertain if these represent very short polarity chrons or geomagnetic intensity fluctuations. Cande and LaBrecque [1974] were able to model small scale magnetic anomalies between Anomalies 5 and $5 \mathrm{~A}$ equally satisfactorily as either short chrons or intensity fluctuations. Cande and Kent [1992b] made a detailed analysis of some of these anom- alies and favored the latter explanation, but to accommodate the ambiguity they proposed designating them as cryptochrons. Of the 54 cryptochrons catalogued by Cande and Kent [1992b], 46 are potentially of normal polarity and only 8 of reverse polarity. They are unevenly distributed in the polarity record: 46 occur in the Oligocene and Paleocene, and thus would affect primarily the statistical properties of segment CK95(2) if found to be real polarity subchrons. For example, adding all the cryptochrons listed for the optimum timescale of Cande and Kent [1995] reduces the gamma index to $k=1.3 \pm 0.3$ in CK95(1) and to $k=0.6 \pm 0.1$ in CK95(2) (Figure 8). However, not all, and perhaps only a few, are likely to be real polarity subchrons. CK95 used a $30 \mathrm{kyr}$ cut-off to separate cryptochrons of uncertain origin from the longer, unambiguous polarity chrons. It is noteworthy that one-half (27) of the 54 cryptochrons identified in CK95 have durations of $10 \mathrm{kyr}$ or less and only 3 have durations longer than $20 \mathrm{kyr}$ (but less than $30 \mathrm{kyr}$ ). We suggest that relatively few cryptochrons, most likely the longer ones, represent polarity reversals.

Detailed magnetostratigraphic investigations have generally failed to identify short polarity chrons in sections where CK95 indicates cryptochrons are abundant. A short core, the Massicore, drilled in Eocene-Oligocene marls from the Italian Marches region, contained a complete magnetostratigraphy from Chron $\mathrm{C} 16 \mathrm{n}$ to Chron $\mathrm{C} 12 \mathrm{r}$ but there were no additional short polarity chrons where CK95 identified cryptochrons in this interval [Lanci et al., 1996]. A rock magnetic

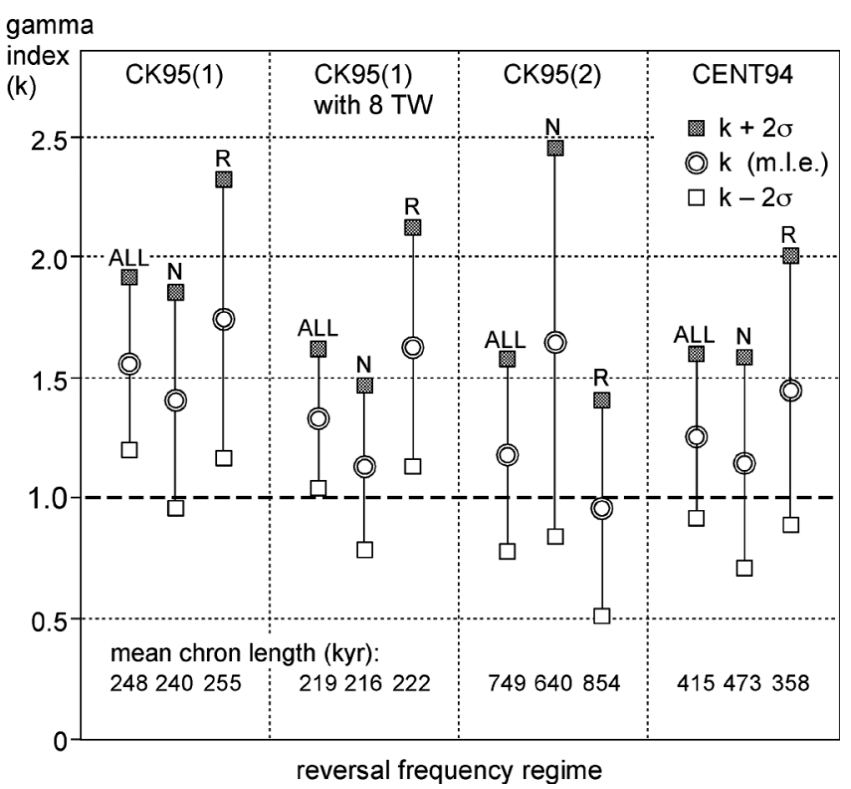

Figure 7. Maximum likelihood estimates of the gamma index $k$ and its $\pm 2 \sigma$ range for the timescale segments CK95(1), CK95(1) with 8 short chrons added, CK95(2) and CENT94. The numbers below each range of $k$ give the mean chron length for the segment in kyr. 
study showed paleointensity fluctuations at the expected locations of the cryptochrons [Lanci and Lowrie, 1997]. Closely sampled Oligocene pelagic sediments from DSDP Site 522 showed consistent decreases in paleointensity that could correspond to cryptochrons [Tauxe and Hartl, 1997]. It might be postulated that the discrete sample spacing was too wide to find these short events. However, an almost continuous highresolution magnetostratigraphy in ODP sites 1218 and 1219, obtained with the on-ship pass-through magnetometer and
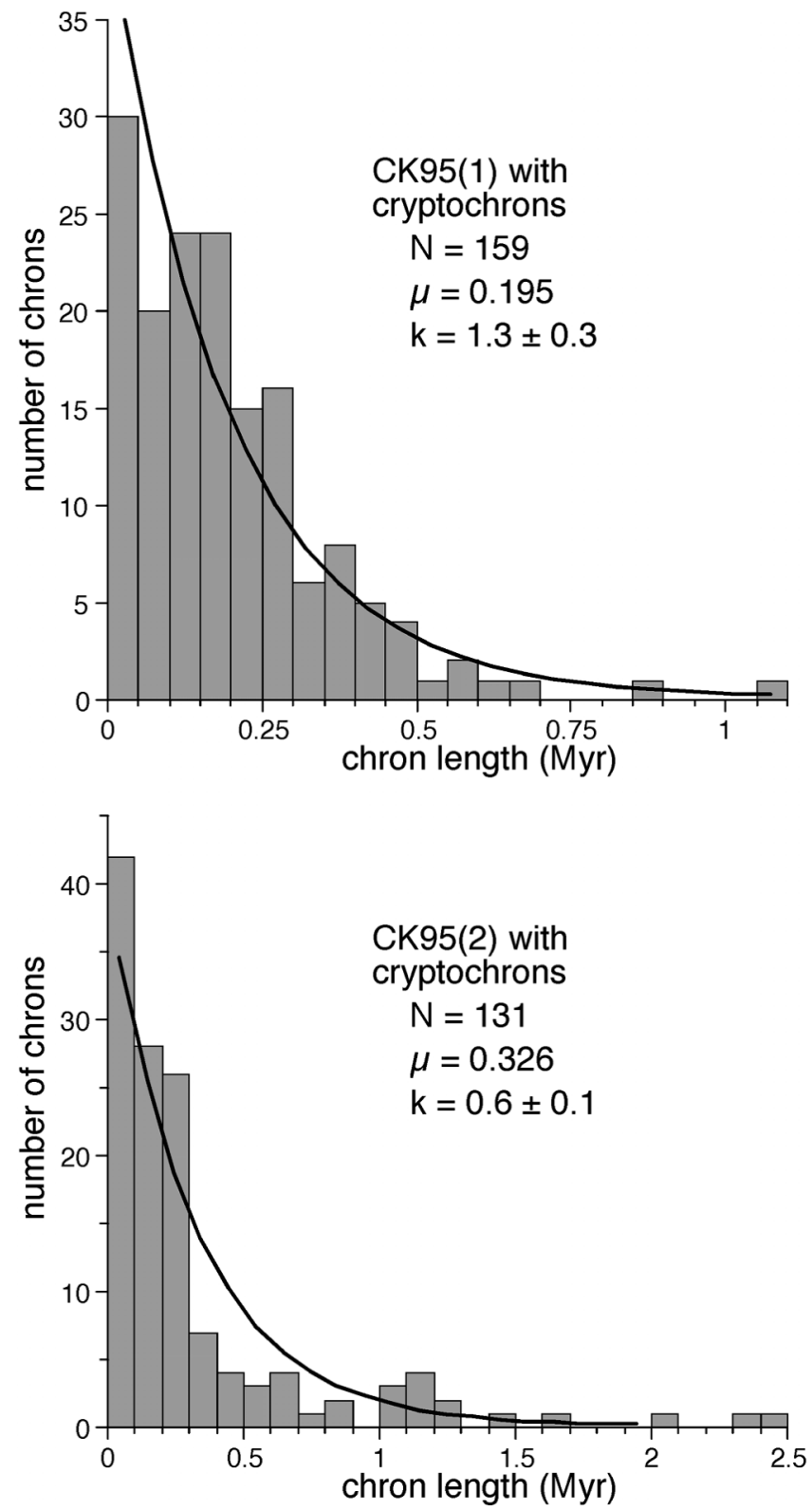

Figure 8. Distributions of chron lengths (Myr) when all cryptochrons predicted in CK95 are added to the two stationary segments CK95(1) and CK95(2). Solid lines are best fit exponential curves.
Table 2. Ages (Ma) of short magnetozones found in magnetostratigraphic studies that can be considered as real polarity subchrons. Ages are calculated with respect to CK95

\begin{tabular}{lrrl}
\hline Subchron & $\begin{array}{r}\text { Young } \\
\text { end }\end{array}$ & $\begin{array}{r}\text { Old } \\
\text { end }\end{array}$ & Reference \\
\hline C1r.2r-1n & 1.201 & 1.211 & Berggren et al. [1995] \\
C4r.2r-1n & 8.606 & 8.664 & Krijgsman \& Kent [2004] \\
C4Ar.1r-1n & 9.097 & 9.117 & Krijgsman \& Kent [2004] \\
C5r.2r-1n & 11.167 & 11.193 & Krijgsman \& Kent [2004] \\
C5r.2r-2n & 11.352 & 11.363 & Krijgsman \& Kent [2004] \\
C5r.3r-1n & 11.555 & 11.584 & Krijgsman \& Kent [2004] \\
C5Dr-1n & 17.793 & 17.854 & Channell et al. [2003] \\
C7Ar-1n & 25.678 & 25.705 & Channell et al. [2003] \\
& & & \\
\hline
\end{tabular}

subsequent u-channel sampling, also showed no short polarity chrons where they were predicted by cryptochrons [Lanci et al., 2002]. Detailed magnetostratigraphic sections in Umbrian carbonate rocks showed variations in paleointensity within the CNPS but no evidence of cryptochrons [Cronin et al., 2001].

There are, however, indications that short polarity chrons not listed in CK95 do exist. For example, the Cobb Mountain Subchron is included in the Late Neogene chronology of Berggren et al. [1995]. Five additional short polarity intervals, each longer than $10 \mathrm{kyr}$, were identified in a detailed magnetostratigraphic study of Middle to Late Miocene sediments from DSDP Site 608 [Krijgsman and Kent, 2004]. Their proposed status as real polarity subchrons was verified on the basis of correlative short polarity intervals reported in ODP Site 854 [Schneider, 1995], ODP Site 1092 [Evans and Channell, 2003], and/or the Orera section in Spain [Abdul Aziz and Langereis, 2004]. Four other features that were also identified in Site 608 were considered by Krijgsman and Kent [2004] to represent very short $(<10 \mathrm{kyr}$ ) geomagnetic excursions associated with fluctuations in field intensity, rather than polarity subchrons. Three of these excursions occur in Chron C5n.2n. In an important test of whether "tiny wiggles" represent polarity chrons or paleointensity fluctuations, Bowles et al. [2003] searched explicitly for short polarity features and measured paleointensity variations in Chron $\mathrm{C} 5 \mathrm{n} .2 \mathrm{n}$ in sediments from ODP Site 887 . They found no polarity subchrons in this interval; instead, paleointensity variations gave a good match to the low-amplitude oceanic magnetic anomalies from which cryptochrons in this interval had been postulated. Thus, even though directional excursions corresponding to the cryptochrons in Chron C5n.2n may sometimes be found (e.g., Evans and Channell [2003]), their very short duration and 

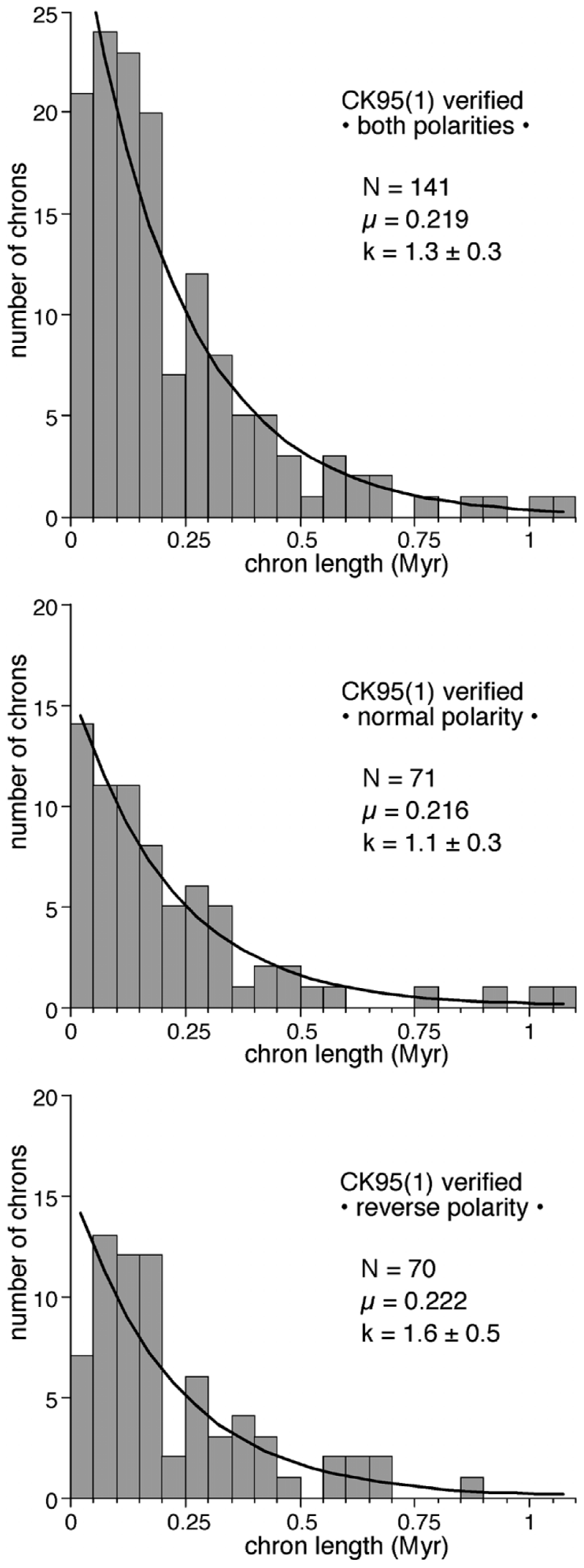

ephemeral character suggest that they do not correspond to global polarity subchrons.

We have incorporated the five additional subchrons identified by Krijgsman and Kent [2004] and used similar criteria (e.g., antipodal directions to the host polarity interval and durations equal to or greater than $10 \mathrm{kyr}$ as estimated from local sedimentation rates) to assess potential new subchrons in recent studies that were made with very close sampling or continuous measurement, and employing modern paleomagnetic techniques. In this way we identified a total of 8 additional short chrons (Table 2), which all occur in the youngest segment of the Cenozoic timescale, CK95(1). When they are included in CK95(1) the distributions of chrons of both polarities and those of only normal polarity are close to exponential although there is a deficiency in short chrons with reverse polarity (Figure 9). The recomputed mean interval length becomes $0.219 \mathrm{Myr}$ and the gamma index is reduced to $k=1.3$, with $95 \%$ fiducial limits that now include $k=1$ (Table 2). The difficulty of finding corresponding short polarity intervals in magnetostratigraphic records suggests that most of the oceanic "tiny wiggles" identified as cryptochrons are due to paleointensity variations and are not part of the reversal sequence. We believe that it is unlikely that forthcoming detailed magnetic stratigraphy will reveal many more additional short chrons than have already been reported, but even a few more would further reduce $k$ to a value even closer to unity.

\section{DISCUSSION}

In preparing geomagnetic polarity timescales no consideration is usually given to the finite duration of a polarity transition, which is thought to last about 4-6 kyr (e.g., Clement and Kent [1984]). This time is included in the lengths of polarity chrons, which are measured between the midpoints of polarity transitions, even though the transitional time can be an appreciable fraction of the durations of some short polarity chrons. McFadden and Merrill [1993] recognized that transitions are not instantaneous and introduced the idea of a dead time of $5 \mathrm{kyr}$ following a reversal during which no new reversal can take place. The result is to increase the effective value of $k$ for a Poisson distribution to slightly greater than 1 .

McFadden and Merrill [1997] characterized reversal behavior by changes in reversal rate instead of chron length. They interpreted the changes of reversal rate as a gradual decrease prior to the CNPS, when it became zero, followed by a gradual increase subsequently. Our analysis differs fundamentally

Figure 9. Distributions of chron lengths (Myr) when the few short polarity intervals found in magnetostratigraphic studies are added to the two stationary segments CK95(1) and CK95(2). Solid lines are best fit exponential curves. 
from theirs because we see evidence for stationary reversal behavior prior to and after the CNPS. In this respect, our point of view is more similar to that of Gallet and Hulot [1997], who regarded the CNPS as representing either an abrupt perturbation of the reversal process or a separate (non)reversal regime rather than being part of a continuous, long-term evolution of reversal rate. The stationarity prior to the CNPS is in agreement with the findings of Hulot and Gallet [2003] that there is little evidence of precursory field behavior that heralded this superchron, contrary to the earlier suggestion of McFadden and Merrill [2000].

Although our analysis reaches similar conclusions, it differs in several ways from that of Gallet and Hulot [1997]. They subdivide the polarity sequence into three segments on the basis of age, at points that differ from ours and for different criteria. Their segment A, covering 130-160 Ma, omits the youngest M-chrons; it is stationary, which we find to be the case for all of CENT94 from 120-160 Ma, including the youngest M-chrons. Segment B of Gallet and Hulot [1997], covering 25-130 Ma, includes the CNPS and is not stationary. Merrill and McFadden [1994] found it inappropriate to consider the CNPS as part of the reversal sequence in statistical analyses; we also omit it from our analysis. In addition, we omit chrons C33n and C33r, which in our view have a similar status to the CNPS. These omissions result in a stationary segment CK95(2). Segment A of Gallet and Hulot [1997], covering 0-25 Ma, is stationary. Our CK95(1) embraces 0-31 Ma and is stationary, a conclusion also reached by Marzocchi [1997].

We note here that the pre-CM29 cryptochrons in the marine anomaly record have the same character as the "tiny wiggles" in the Cenozoic record and, moreover, have not been correlated satisfactorily in magnetostratigraphic studies. We have excluded the pre-CM29 features because the reversal sequence they might represent has not been verified and the anomalies may well be due to paleointensity variations. If they should be found to represent reversals, they should then be regarded as part of a (higher frequency) reversal regime distinct from CENT94, as CK95(1) is distinct from CK95(2).

The increasing reversal rate following the CNPS in the analyses of McFadden and Merrill [1997] and McFadden and Merrill [2000] arises because they consider the C-sequence in its entirety to be non-stationary, whereas we regard it as composed of two reversal regimes, each of which is stationary. Chrons C33r and C33n immediately following the CNPS, if included in CK95(2), would make this segment barely non-stationary. However, they are exceptionally long and might well be classified with the CNPS; together, these chrons can even be considered as a different reversal regime with an exceptionally long mean interval length of 15.7 Myr.

In some previous analyses of reversal statistics, values of $k$ substantially greater than 1 were regarded as due to either an incomplete record or some process that inhibits reversals. McFadden and Merrill [1984] regarded a value of $k$ greater than 1 as an indicator for the fraction of missed short polarity chrons that were not resolved in the polarity timescales because of concatenation with other chrons. They predicted that about $46 \%$ of the polarity intervals in the Csequence contained one or more unresolved short chrons. This prediction has not stood the test of observation. The most detailed analysis of the Late Cretaceous and Cenozoic reversal record, CK95, identified 54 locations where short polarity chrons might occur. Yet few of these cryptochrons have been confirmed as polarity intervals, as summarized above. Moreover, the addition of only 8 verified subchrons in CK95(1) has reduced $k$ to be statistically indistinguishable from 1 (Poissonian, taking into account finite transition time), whereas CENT94 and CK95(2) already have gamma indices statistically indistinguishable from 1. Should more subchrons be confirmed, they would further reduce $k$ to a value even closer to unity in each regime. Interestingly, there is remarkably little difference in the $k$-values for CK95(1) if only 8 selected subchrons from magnetostratigraphy or all 17 possible cryptochrons from CK95 are added. This is an indication that the statistical properties are becoming very robust. The general absence of short polarity intervals in the CNPS may indicate that the occurrence of cryptochrons is a function of reversal rate, i.e., more might be expected to occur when the geodynamo is already reversing frequently, as in segment CK95(1).

In another scenario, the reversal itself is treated as a special event, following which there is an 'inhibition' period of 40-50 kyr in which the probability of another reversal is reduced [McFadden and Merrill, 1993]. Such an inhibition period, whose physical origin is unclear, was introduced in order to explain elevated values of $k$ when the mean interval length was short. However, given our observation that there is no significant change in gamma index $k$ with mean interval length, and that $k$ is close to unity in each reversal regime, the concept of an inhibition period is unnecessary.

Our analysis leads to the following conclusions.

(1) The record of reversal history over the past $160 \mathrm{Myr}$ is composed of distinct segments in which the reversal process was stationary and characterized by a gamma index not distinctly different from unity, i.e. a Poisson process.

(2) Each segment may be looked on as a different regime of reversal behavior, either intrinsic to the dynamo process or triggered externally, e.g., see Gallet and Hulot [1997]. Further progress in understanding the significance of the reversal regimes will require integration of other relevant types of data, such as paleosecular variation [McFadden et al., 1991]. 
(3) From one regime to another there is no significant change in gamma index $k$, but the average reversal rates shift abruptly and markedly, for example by a factor 3 in the Cenozoic.

(4) The Poisson model, with $k$ indistinguishable from 1, appears to be a fundamental feature of geomagnetic field reversals. It is not only characteristic of the last $160 \mathrm{Myr}$ as documented here for CK95(1), CK95(2), and CENT94. It is also observed for a $30 \mathrm{Myr}$ interval in the Late Triassic, for which an astronomically calibrated geomagnetic polarity timescale has been developed [Kent and Olsen, 1999].

Acknowledgements. This is contribution 6552 of Lamont Doherty Earth Observatory and contribution 1323 of the Institute of Geophysics, ETH Zürich. DVK is grateful to the ETH Zürich for partial support during a sabbatical visit. We thank Ron Merrill and Yves Gallet for helpful reviews.

\section{REFERENCES}

Abdul Aziz, H., and C. G. Langereis, Geomagnetic polarity timescales and reversal frequency regimes, in Chapman Conference on Timescales of the Geomagnetic Field, edited by J. E. T. Channell, D. V. Kent, W. Lowrie, and J. Meert, American Geophysical Union, Gainesville, Florida, 2004.

Alvarez, W., M. A. Arthur, A. G. Fischer, W. Lowrie, G. Napoleone, I. Premoli Silva, and W. M. Roggenthen, Upper Cretaceous-Paleocene magnetic stratigraphy at Gubbio, Italy. V. Type section for the Late Cretaceous-Paleocene geomagnetic reversal time scale, Geol. Soc. Amer. Bull., 88, 383-389, 1977.

Berggren, W. A., F. J. Hilgen, C. G. Langereis, D. V. Kent, J. D. Obradovich, I. Raffi, M.E. Raymo, and N. J. Shackleton, Late Neogene chronology: New perspectives in high-resolution stratigraphy, Geol. Soc. Amer. Bull., 107, 1272-1287, 1995.

Bowles, J., L. Tauxe, J. Gee, D. McMillan, and S. Cande, Source of tiny wiggles in chron C5A: A comparison of sedimentary relative intensity and marine magnetic anomalies, Geochem., Geophys., Geosys., 4, doi:10.1029/2002GC000489, 2003.

Cande, S., R. L. Larson, and J. L. LaBrecque, Magnetic lineations in the Pacific Jurassic quiet zone, Earth Planet. Sci. Lett., 41, 434-440, 1978.

Cande, S. C., and D. V. Kent, A new geomagnetic polarity time scale for the Late Cretaceous and Cenozoic, J. Geophys. Res., 97, 13,917-13,951, 1992a.

Cande, S. C., and D. V. Kent, Ultra-high resolution marine magnetic anomaly-profiles: a record of continuous paleointensity variations?, J. Geophys. Res., 97, 15,075-15,083, 1992b.

Cande, S. C., and D. V. Kent, Revised calibration of the geomagnetic polarity timescale for the Late Cretaceous and Cenozoic, $J$. Geophys. Res., 100, 6093-6095, 1995.

Cande, S. C., and Y. Kristoffersen, Late Cretaceous magnetic anomalies in the North Atlantic, Earth Planet. Sci. Lett., 35, 215-224, 1977.
Cande, S. C., and J. L. LaBrecque, Behaviour of the earth's palaeomagnetic field from small scale marine magnetic anomalies, Nature, 247, 26-28, 1974.

Channell, J. E. T., and E. Erba, Early Cretaceous polarity chrons CM0 to CM11 recorded in northern Italian land sections near Brescia, Earth Planet. Sci. Lett., 108, 161-179, 1992.

Channell, J. E. T., E. Erba, G. Muttoni, and F. Tremolada, Early Cretaceous magnetic stratigraphy in the APTICORE drill core and adjacent outcrop at Cismon (Southern Alps, Italy), and correlation to the proposed Barremian-Aptian boundary stratotype, Geol. Soc. Amer. Bull., 112, 1430-1443, 2000.

Channell, J. E. T., E. Erba, M. Nakanishi, and K. Tamaki, Late Jurassic-Early Cretaceous time scales and oceanic magnetic anomaly block models, in Geochronology, Timescales, and Stratigraphic Correlation, Special Publication, SEPM, edited by W.A. Berggren, D. V. Kent, M. Aubry, and J. Hardenbol, pp. 51-64, 1995.

Channell, J. E. T., W. Lowrie, and F. Medizza, Middle and Early Cretaceous magnetic stratigraphy from the Cismon section, northern Italy, Earth Planet. Sci. Lett., 42, 153-166, 1979.

Channell, J. E. T., and F. Medizza, Upper Cretaceous and Paleogene magnetic stratigraphy and biostratigraphy from the Venetian (Southern) Alps, Earth Planet. Sci. Lett., 55, 419-432, 1981.

Clement, B. M., and D. V. Kent, Latitudinal dependency of geomagnetic polarity transition durations, Nature, 310, 488-491, 1984

Cox, A., Lengths of geomagnetic polarity intervals, J. Geophys. Res., 73, 3247-3260, 1968.

Cronin, M., L. Tauxe, C. Constable, P. Selkin, and T. Pick, Noise in the quiet zone, Earth Planet. Sci. Lett., 190, 13-30, 2001.

Evans, H. F., and J. E. T. Channell, Upper Miocene magnetic stratigraphy at ODP site 1092 (sub-Antarctic South Atlantic): recognition of 'cryptochrons' in C5n.2n, Geophysical J. Intl., 153, 483-496, 2003.

Fisher, N. I., T. Lewis, and B. J. Embleton, Statistical Analysis of Spherical Data, Cambridge University Press, 1987.

Gaffin, S., Analysis of scaling in the geomagnetic polarity reversal record, Phys. Earth Planet. Inter., 57, 284-290, 1989.

Gallet, Y., and V. Courtillot, Geomagnetic reversal behaviour since 100 Ma, Phys. Earth Planet. Inter., 92, 235-244, 1995.

Gallet, Y., and G. Hulot, Stationary and nonstationary behaviour within the geomagnetic polarity time scale, Geophys. Res. Lett., 24, 1875-1878, 1997.

Handschumacher, D. W., W. W. Sager, T. W. C. Hilde, and D. R. Bracey, Pre-Cretaceous evolution of the Pacific plate and extension of the geomagnetic polarity reversal time scale with implications for the origin of the Jurassic "Quiet Zone", Tectonophysics, 155, 365-380, 1988.

Harland, W. B., R. L. Armstrong, A. V. Cox, L. E. Craig, A. G. Smith, and D.G. Smith, A Geologic Time Scale 1989, 263 pp., Cambridge University Press, Cambridge, 1990.

Heirtzler, J. R., G. O. Dickson, E. M. Herron, W. C. Pitman, III, and $\mathrm{X}$. Le Pichon, Marine magnetic anomalies, geomagnetic field reversals and motions of the ocean floor and continents, J. Geophys. Res., 73, 2119-2136, 1968.

Hulot, G., and Y. Gallet, Do superchrons occur without any palaeomagnetic warning?, Earth Planet. Sci. Lett., 210, 191-201, 2003. 
Kent, D. C., and P. E. Olsen, Astronomically tuned geomagnetic polarity timescale for the Late Triassic, J. Geophys. Res., 104, 12,831-12,841, 1999.

Kent, D. V., and F. M. Gradstein, A Cretaceous and Jurassic geochronology, Geol. Soc. Am. Bull., 96, 1419-1427, 1985.

Krijgsman, W., and D. V. Kent, Non-uniform occurrence of short-term polarity fluctuations in the geomagnetic field? New results from Middle to Late Miocene sediments of the North Atlantic (DSDP Site 608), AGU Monograph, 2004.

LaBrecque, J. L., D. V. Kent, and S. C. Cande, Revised magnetic polarity time scale for Late Cretaceous and Cenozoic time, Geology, 5, 330-335, 1977.

Lanci, L., J. M. Pares, and J. E. T. Channell, Miocene-Oligocene magnetostratigraphy from Equatorial Pacific sediments (ODP Site 1218, Leg 199), Eos Trans. AGU, 83 (47), Fall Meeting Suppl., Abstract PP21D-09, 2002.

Lanci, L., and W. Lowrie, Magnetostratigraphic evidence that "tiny wiggles" in the marine magnetic anomaly record represent geomagnetic paleointensity variations, Earth Planet. Sci. Lett., 148, 581-592, 1997.

Lanci, L., W. Lowrie, and A. Montanari, Magnetostratigraphy of the Eocene-Oligocene boundary in a short continental drill-core, Earth Planet. Sci. Lett., 143, 37-48, 1996.

Larson, R. L., and T. W. C. Hilde, A revised time scale of magnetic reversals for the Early Cretaceous and Late Jurassic, J. Geophys. Res, 80, 2586-2594, 1975.

Lowrie, W., Polynomial representation of geomagnetic polarity reversal sequences, EoS Trans. $A G U, 78$, F193, 1997.

Lowrie, W., and W. Alvarez, Upper Cretaceous-Paleocene magnetic stratigraphy at Gubbio, Italy. III. Upper Cretaceous magnetic stratigraphy, Geol. Soc. Amer. Bull., 88, 374-377, 1977.

Lowrie, W., and W. Alvarez, One hundred million years of geomagnetic polarity history, Geology, 9, 392-397, 1981.

Lowrie, W., and W. Alvarez, Lower Cretaceous magnetic stratigraphy in Umbrian pelagic limestone sections, Earth Planet. Sci. Lett., 71, 315-328, 1984.

Lowrie, W., W. Alvarez, G. Napoleone, K. Perch-Nielsen, I. Premoli Silva, and M. Toumarkine, Paleogene magnetic stratigraphy in Umbrian pelagic carbonate rocks: the Contessa sections, Gubbio, Geol. Soc. Amer. Bull., 93, 414-432, 1982.

Lowrie, W., and J. E. T. Channell, Magnetostratigraphy of the Jurassic-Cretaceous boundary in the Maiolica limestone (Umbria, Italy), Geology, 12, 44-47, 1984.

Lowrie, W., and D. V. Kent, Geomagnetic reversal frequency since the Late Cretaceous, Earth Planet. Sci. Lett., 62, 305-313, 1983.

Lutz, T. M., and G. S. Watson, Effects of long-term variation on the frequency spectrum of the geomagnetic reversal record, Nature, 334, 240-242, 1988.

Marzocchi, W., Missing reversals in the geomagnetic polarity timescale: their influence on the analysis and in constraining the process that generates geomagnetic reversals, J. Geophys. Res., 102, 5157-5171, 1997

McFadden, P. L., Statistical tools for the analysis of geomagnetic reversal sequences, J. Geophys. Res., 89, 3363-3372, 1984.
McFadden, P. L., and R. T. Merrill, Lower mantle convection and geomagnetism, J. Geophys. Res., 89, 3354-3362, 1984.

McFadden, P. L., and R. T. Merrill, Inhibition and geomagnetic field reversals, J. Geophys. Res., 98, 6189-6199, 1993.

McFadden, P. L., and R. T. Merrill, Asymmetry in the reversal rate before and after the Cretaceous Normal Polarity Superchron, Earth Planet. Sci. Lett., 149, 43-47, 1997.

McFadden, P. L., and R. T. Merrill, Evolution of the geomagnetic reversal rate since $160 \mathrm{Ma}$ : Is the process continuous?, J. Geophys. Res., 105, 28,455-28,460, 2000.

McFadden, P. L., R. T. Merrill, M. W. McElhinny, and S. Lee, Reversals of the earth's magnetic field and temporal variations of the dynamo families, J. Geophys. Res., 96, 3923-3933, 1991.

Mead, G. A., Correlation of Cenozoic-Late Cretaceous geomagnetic polarity time scales: An Internet archive, J. Geophys. Res., 101 (8107-8109), 1996.

Merrill, R. T., and P. L. McFadden, Geomagnetic field stability: Reversal events and excursions, Earth Planet. Sci. Lett., 121, 57-69, 1994.

Naidu, P. S., Statistical structure of geomagnetic field reversals, $J$. Geophys. Res., 76, 2649-2662, 1970.

Ogg, J. G., M. B. Steiner, F. Oloriz, and J. M. Tavera, Jurassic magnetostratigraphy, 1. Kimmeridgian-Tithonian of Sierra Gorda and Carcabuey, southern Spain, Earth Planet. Sci. Lett., 71, 147-162, 1984.

Phillips, J. D., Time variation and asymmetry in the statistics of geomagnetic reversal sequences, J. Geophys. Res., 82, 835-843, 1977.

Sager, W. W., C. J. Weiss, M. A. Tivey, and H. P. Johnson, Geomagnetic polarity reversal model of deep-tow profiles from the Pacific Jurassic Quiet Zone, J. Geophys. Res., 103, 5269-5286, 1998.

Schneider, D. A., Paleomagnetism of some Leg 138 sediments: Detailing Miocene magnetostratigraphy, Proceedings of the Ocean Drilling Program Scientific Results, 138, 59-72, 1995.

Steiner, M. B., J. G. Ogg, G. Melendez, and L. Sequeiros, Jurassic magnetostratigraphy, 2. Middle-Late Oxfordian of Aguilon, Iberian Cordillera, northern Spain, Earth Planet. Sci. Lett., 76, $151-166,1985$.

Tarduno, J., W. Lowrie, W. V. Sliter, T. J. Bralower, and F. Heller, Reversed polarity characteristic magnetizations in the Albian Contessa section, Umbrian Apennines, Italy: Implications for the existence of a mid-Cretaceous mixed polarity interval, J. Geophys. Res., 97, 241-271, 1992.

Tarduno, J. A., Brief reversed polarity interval during the Cretaceous Normal Polarity Superchron, Geology, 18, 683-686, 1990.

Tauxe, L., and P. Hartl, 11 million years of Oligocene geomagnetic field behavior, Geophys. J. Intl., 128, 217-229, 1997.

VandenBerg, J., and A. A. H. Wonders, Paleomagnetic evidence of large fault displacement around the Po-Basin, Tectonophysics, 33, 301-320, 1976.

Dennis V. Kent, Lamont-Doherty Earth Observatory, Palisades, NY 10964. (dvk@1deo.columbia.edu)

William Lowrie, Institute of Geophysics, ETH Hönggerberg, 8093

Zürich, Switzerland. (lowrie@mag.ig.erdw.ethz.ch) 